\title{
THE APRIL MEETING AT STANFORD UNIVERSITY
}

The three hundred sixtieth meeting of the American Mathematical Society was held at Stanford University on Saturday, April 15, 1939. A general session was held Saturday morning and another in the afternoon. Professors H. F. Blichfeldt, A. D. Michal, Gabor Szegö, and W. M. Whyburn presided at various times. At the morning session Professor T. Y. Thomas of the University of California at Los Angeles gave an address entitled Embedding theorems in differential geometry. The attendance included the following thirty-two members of the Society:

H. M. Bacon, Clifford Bell, B. A. Bernstein, H. F. Blichfeldt, C. R. Bubb, F. W. Dresch, C. A. Hayes, E. R. Hedrick, R. D. James, Hans Lewy, A. T. Lonseth, Rhoda Manning, W. A. Manning; A. E. Marston, A. D. Michal, C. B. Morrey, W. H. Myers, C. D. Olds, A. C. Olshen, R. W. Rector, R. M. Robinson, E. L. Ross, W. H. Simons, Pauline Sperry, Gabor Szegö, T. Y. Thomas, J. V. Uspensky, R. K. Wakerling, W. F. Whitmore, W. M. Whyburn, B. C. Wong, Max Zorn.

On Saturday afternoon a tea for members of the Society and their friends was given by Professor and Mrs. Szegö at their home.

Titles of papers read at the meeting follow. Those whose abstract numbers are followed by the letter $t$ were read by title.

1. R. K. Wakerling: On the loci of $(k+1)$-secant $k$-spaces of a curve in r-space. (Abstract 45-5-247.)

2. R. A. Favila: A surface with doubly stratifiable directrices. (Abstract 45-5-175.)

3. B. A. Bernstein: Groups and abelian groups in terms of negative addition. (Abstract 45-5-161.)

4. Max Wyman: Non-holonomic covariant vector fields. (Abstract 45-5-256.)

5. C. B. Morrey: Multiple Denjoy-Perron integrals. (Abstract 45-5214.)

6. A. T. Lonseth: The problem of Plateau in hyperbolic space. (Abstract 45-5-202.)

7. Max Zorn: Menger-Brouwer dimension in subanalytic spaces. Preliminary report. (Abstract 45-5-258.)

8. A. D. Michal and A. B. Mewborn: General projective differential geometry of paths. (Abstract 45-5-210.)

9. L. F. Walton: On the theory of ideal numbers. Preliminary report. (Abstract 45-5-251.)

10. H. A. Arnold: Note on completely continuous differentials. (Abstract 45-5-153-t.) 
11. R. M. Robinson: On numerical bounds in Schottky's theorem. (Abstract 45-5-233-t.)

12. O. G. Harrold: Invariance of the dimensionality of a compact metric space under certain continuous transformations. (Abstract 455-182-t.)

13. Max Wyman: Postulates for the determination of a non-holonomic linear connection. (Abstract 45-5-257-t.)

14. P. M. Swingle: A finitely containing connected set. (Abstract 45-5-241-t.)

15. Harlan C. Miller: A separation theorem. (Abstract 45-5-211-t.)

16. Harlan C. Miller: On the characterization of a certain type of continuous curve. (Abstract 45-5-212-t.)

17. Clifford Bell: Solution of numerical equations. (Abstract 45-5160-t.)

18. A. D. Michal and A. B. Mewborn: General flat projective geometry. (Abstract 45-7-271-t.)

T. M. Putnam, Associate Secretary 